\title{
IMPROVEMENT THE PERFORMANCE OF COMPOSITE PCM PARAFFIN-BASED INCORPORATE WITH VOLCANIC ASH AS HEAT STORAGE FOR LOW-TEMPERATURE APPLICATION
}

\author{
Dwi Rahmalina $\bowtie$ \\ Department of Mechanical Engineering ${ }^{1}$ \\ drahmalina@univpancasila.ac.id \\ Dwi Chandra Adhitya \\ Department of Mechanical Engineering ${ }^{1}$ \\ Reza Abdu Rahman \\ Department of Mechanical Engineering ${ }^{1}$ \\ Ismail \\ Department of Mechanical Engineering ${ }^{1}$ \\ ${ }^{1}$ Universitas Pancasila \\ Jalan Srengseng Sawah, Jagakarsa, Jakarta Selatan, \\ DKI Jakarta, Indonesia, 12640
}

$\triangle$ Corresponding author

\begin{abstract}
Paraffin is well known thermal energy storage with the high latent heat of fusion. Unfortunately, low thermal conductivity and low melting temperature inhibit large-scale applications for lower temperature applications like solar water heaters and desalination. The addition of high thermal conductivity material can increase the thermal conductivity of paraffin and increase the melting temperature of paraffin. In this study, a new approach is taken by using volcanic sand as thermal conductivity enhancement material. The properties of the sand are examined. The chemical composition of the sand is dominated by $\mathrm{Fe}(51.23 \%), \mathrm{Fe}_{2} \mathrm{O}_{3}(23.24 \%)$ and $\mathrm{SiO}_{2}(11 \%)$, which are known as good thermal conductivity materials. Six different compositions of paraffin/sand (weight ration) are tested to observe the melting and vapor temperature of the composite. Adding sand (with granule size of $44 \mu \mathrm{m}$ ) by $30 \mathrm{wt} \%$ can accelerate the charging rate by $25 \%$ compared to pure paraffin, where the discharging rate is increased significantly by $17.8 \%$. The supercooling degree of the composite is only $1{ }^{\circ} \mathrm{C}$, where pure paraffin has a supercooling degree by $8{ }^{\circ} \mathrm{C}$. The charging and discharging characteristics for each sample are discussed in detail within the article. Overall, the addition of volcanic sand improves paraffin's charging and discharging rate, reducing the supercooling degree and can be considered a convenient method to improve the paraffin performance as latent heat storage.
\end{abstract}

Keywords: composite phase change material, partial phase change, paraffin, thermal energy storage, volcanic ash.

DOI: $10.21303 / 2461-4262.2022 .002055$

\section{Introduction}

Paraffin-based phase change material as thermal energy storage is highly recommended for low temperature application because it is safer, more stable, non-corrosive, has a reasonably wide temperature range $\left(5-80^{\circ} \mathrm{C}\right)$ and low price [1-3]. The main challenges of applying paraffin as PCM (Phase Change Material) are low thermal conductivity and low enthalpy of phase change [4-6]. An alternative solution to improve the nature of paraffin as thermal energy storage is through integration with sensible heat materials, such as water, sand and rocks. The application of sand is recommended because it has good thermal conductivity, abundant availability and economically feasible [7].

Many studies were done in order to improve the performance of paraffin-based PCM for thermal storage applications. The improvement for the thermal conductivity of PCM by using improving the composite phase change material paraffin wax (RT60) and graphite (GNP) [8]. The 
improvement is also done by using polyaniline to improve the thermal reliability [9]. Another method is done by using aluminum by $8 \% \mathrm{w} / \mathrm{w}$ can increase the thermal conductivity up to $0.63 \mathrm{~W} / \mathrm{mK}$ [10].

The addition of additive material can be considered as an easy and cheap method to improve paraffin performance in thermal energy storage. For lower temperature applications, the addition of sensible heat material like water, rock and sand is considered as the easiest and cheapest way to enhance the paraffin performance [11]. The recommended working area for sensible-PCM as thermal storage is in the solid-liquid transition phase, rather than the liquid-vapor or the solid-solid phase [12-14]. An experimental study is conducted to evaluate the performance of composite sensible-latent storage for hot water applications by utilizing commercial paraffin grade and hydrate salt mixture and found that the heat storage capacity is increased for the system [15]. Furthermore, a combined sensible-latent material could be used to overcome the weakness of PCM material [16]. However, in most cases, it leads to another problem, such as higher cost and material compatibilities issues. Therefore, these barriers must be taken into account in the addition of sensible material.

The addition of sensible material should be appropriately taken because it will decrease the total amount of the paraffin incorporated in the PCM and thus, the overall thermal capacity will be reduced. From the previous studies, the maximum amount of the additive in the PCM should be equal to or lower than $50 \%$ [17]. Sand is considered as a well-known sensible thermal storage material. The application of sand is recommended because it has good thermal conductivity, abundant availability and low cost [18-20]. There are no detailed reports for the type, properties, chemical elements and grain size of sand for paraffin as thermal energy storage. Furthermore, when the sand is added into PCM, the mass fraction between sand and PCM should be stated clearly, including the mass fraction between sand and PCM [21].

Among the various types of sand, in this study, let's use the sand from volcanic ash. The main reasons for choosing the volcanic ash are the bulk size of the sand generally more refined which is suitable for microencapsulation [22] without an extended process for particle size reduction [23] and vast availability in Indonesia. The objectives of our study are to study the effect of adding sand into paraffin mixture with respect to the thermal performance of the PCM, especially for the supercooling degree, charging and discharging rate (time and temperature range). When the all thermal performance is obtained, it can be used as specific reference for the application of PCM in thermal storage application [24-31].

\section{Materials and methods}

\section{1. Materials preparation}

The sand from volcanic ash has no Material Safety Data Sheet (MSDS) and needs to be examined to acquire its properties. Obtaining a uniform sand size will facilitate the process of testing the intensive nature of the sand; thus, the test is started with screening the particle size to get a uniformed size before the further test. Sand (100 grams) is screened by using the sieve method (Malvern 2000, NIST 906-1) with the targeted size is $74 \mu \mathrm{m}$ and $44 \mu \mathrm{m}$. The intensive test is designed to determine the density of the sand. The chemical composition is examined through atomic absorption spectroscopy (Shimadzu Atomic Absorption Spectrophotometer AA-6300, ASTM D 4691-17) to acquire the chemical compositions of the sand; then, a small portion of each size is tested independently for the density (Quantachrome Instruments Ultrapyc 1200e, ASTM D-1298). By using a standardized test, let's expect to get a better standardized for the sand characterization before adding into the PCM. The paraffin wax used in this test is the paraffin wax market grade 155/160 (CAS: 8002-74-2).

Particle size screening of the sand is carried out at the beginning to obtain a homogenous grain size for the process by using a particle size distribution apparatus. The screening results show there is $39.65 \%$ from bulk material has size $74 \mu \mathrm{m}$ and $41.78 \%$ of $74 \mu \mathrm{m}$ material has a size of $44 \mu \mathrm{m}$. The result shows a good indicator that without having any mechanical modification, it can be obtained $39.65 \%$ of the minimum targeted size $(74 \mu \mathrm{m})$ of the bulk material. It means there is no need for extra cost for processing the bulk volcanic ash to the targeted size. The density for each size is $2.78 \mathrm{~g} / \mathrm{cc}$ for $74 \mu \mathrm{m}$ and $2.76 \mathrm{~g} / \mathrm{cc}$ for $44 \mu \mathrm{m}$. The density of $44 \mu \mathrm{m}$ is lower than $74 \mu \mathrm{m}$ because as the grain size decreases, the surface area decreased as well. The sand that is used in this 
research is categorized as volcanic ash sand, which contains various chemical elements. The atomic absorption spectrophotometer is used to map the details of the chemical composition of the sand. Fig. 1 shows the composition of the chemical composition of the sand.

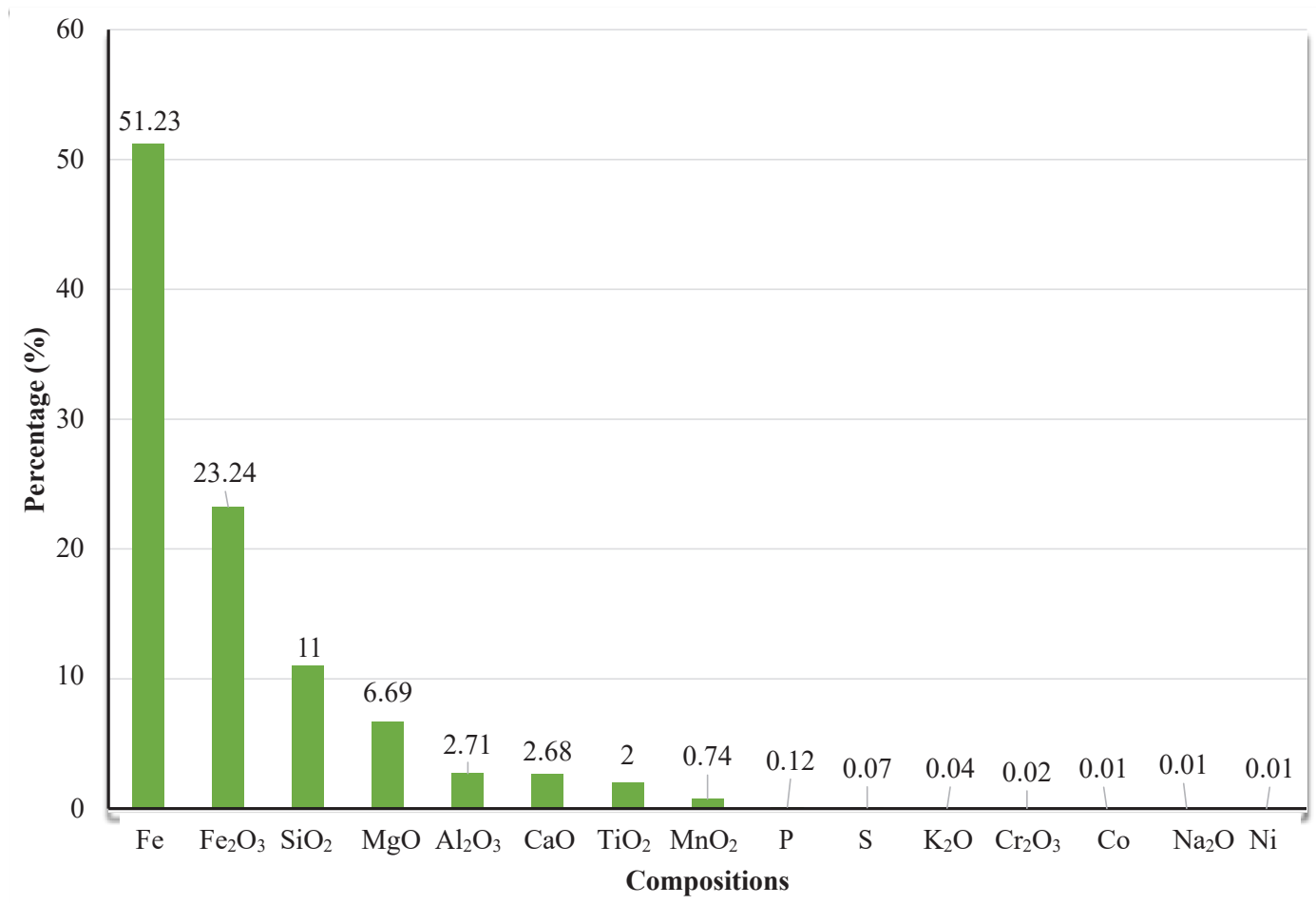

Fig. 1. Chemical composition of the sand

\section{2. Experiment Method}

After examining sand, six different samples were prepared according to the mass fraction and also the particle size of the sand (Table 1). Each sample has 20 grams of mass. The sand is added to liquid phase paraffin and mixed carefully to ensure proper distribution within the sample.

\section{Table 1}

The details of the sample

\begin{tabular}{cccc}
\hline Sample & Paraffin (wt \%) & Sand (wt \%) & The particle size of the sand \\
\hline$S_{0}$ & 100 & 0 & - \\
$S_{1}$ & 90 & 10 & $74 \mu \mathrm{m}$ \\
$S_{2}$ & 90 & 10 & $44 \mu \mathrm{m}$ \\
$S_{3}$ & 70 & 30 & $74 \mu \mathrm{m}$ \\
$S_{4}$ & 70 & 30 & $44 \mu \mathrm{m}$ \\
$S_{5}$ & 50 & 50 & $74 \mu \mathrm{m}$ \\
$S_{6}$ & 50 & 50 & $44 \mu \mathrm{m}$
\end{tabular}

The prepared sample was tested by using a heat exchanger model regenerator with internal tube for heat transfer fluid for charging the sample. The heating rate was maintained at a constant rate to monitor the temperature and phase change of the sample. From the charging test, initial melting temperature $\left(T_{m e l t}\right)$, the saturated melting temperature $\left(T_{\text {Fmelt }}\right)$, the initial vapor temperature $\left(T_{\text {vap }}\right)$, the duration for each temperature changes are obtained and taken as total charging time. The charging test is limited to the initial vapor point $\left(T_{v a p}\right)$ by considering the application of the material for unpressurized bed storage to minimize the cost of the bed storage. For the 
discharging test, the sample was placed at monitored room temperature and cooled down with natural convection. The natural convection for discharging is chosen to minimize the error in temperature reading when the sample is solidifying as it is affected by the supercooling phenomenon. The initial solidifying temperature $\left(T_{\text {sol }}\right)$, the saturated solid temperature $\left(T_{F s o l}\right)$, ambient temperature $\left(T_{a m b}\right)$ and total discharging time are obtained from this test. Despite how careful the measurement is conducted, the deviation of temperature measurement should be considered specifically for thermal inertia on the sample, the deviation of the apparatus for the temperature measurement where the average deviation is $+0.532{ }^{\circ} \mathrm{C}$.

\section{Results}

\section{1. Results of charging test}

The paraffin undergoes three times of phase transition along the charging process namely solid to initial liquid phase (sensible stage 1), initial liquid phase to saturated liquid (phase change transition), and saturated liquid to the initial vapor point (sensible stage 2). Time and temperature are using to plot the graphical model as time versus temperature function to present the phase change at each transition. Fig. 2 shows a graphical presentation for the time vs temperature changes for the performance of pure paraffin.

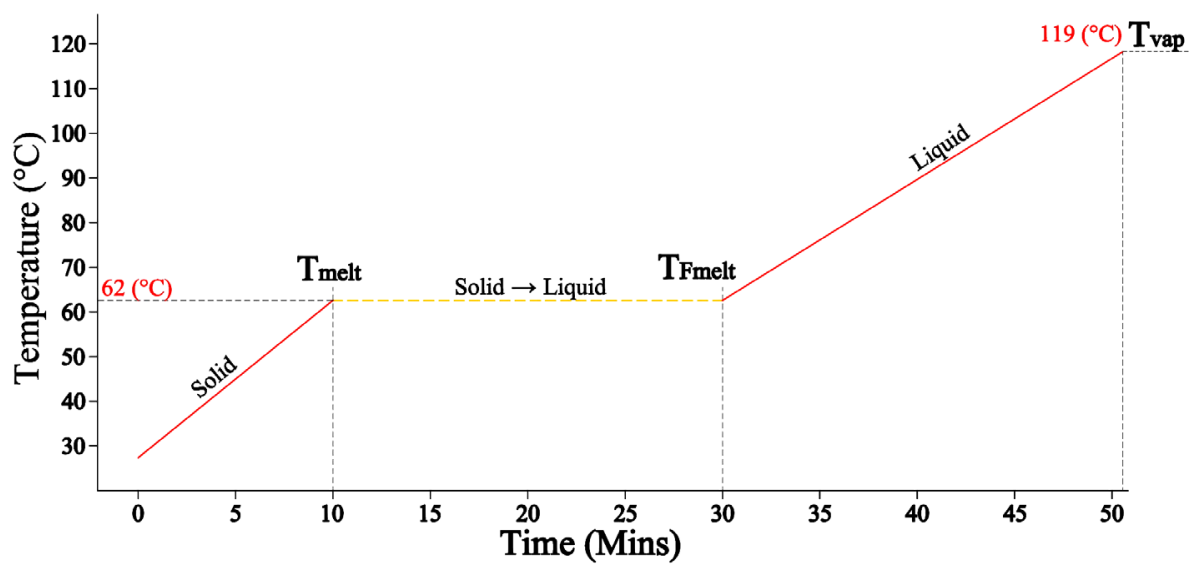

Fig. 2. The time vs temperature changes for pure paraffin during charging

During charging processes, the paraffin experienced two sensible heat (red sloped line), and it shows that the sensible heat under liquid phase to reach initial vapor point $\left(T_{F m e l t}\right.$ to $\left.T_{\text {vap }}\right)$ takes longer time (22 minutes) compared to sensible heat under solid phase $\left(T_{a m b}\right.$ to $\left.T_{m e l t}\right)$ which just takes 10 minutes. It is clear evidence that during the liquid phase, the paraffin has lower thermal conductivity than the solid phase, which affected the heat transfer process. It can also be seen during phase change transition (brown plateau line) the time required to reach a saturated melting point $\left(T_{\text {Fmelt }}\right)$ from the initial melting point $\left(T_{\text {melt }}\right)$ is increased as well. From the experiment, it found that the total charging time for 100 grams pure paraffin to reach the initial vapor point $\left(T_{\text {vap }}\right)$ at $119^{\circ} \mathrm{C}$ takes 52 minutes.

Once the characteristic of pure paraffin during charging and discharging has been obtained, the other samples (Table 1) were tested by the same method. Fig. 3 shows the charging test where all the essential parameters from the test were summarized within the figure.

All the samples have the same characteristic that none of the samples experienced fully latent heat during phase change. After the sample reach melting temperature $\left(T_{\text {melt }}\right)$, the temperature within the sample increase slowly (black dashed line), which indicates that the latent heat from paraffin and sensible heat from sand occurs (partial phase change) [22]. The duration of partial phase change is getting shorter as the sand concentration increased. From the data in Fig. 3, it shows that all the samples are reached the initial melting temperature between $9-10$ mins at $61-63{ }^{\circ} \mathrm{C}$, which just slightly different from pure paraffin. In contrast, the total charging time and the vapor temperature $\left(T_{\text {vap }}\right)$ vary from pure paraffin. The vapor temperature of the composite PCM is higher 
than pure paraffin, with the highest vapor point is reached by $S_{4}$ at $127^{\circ} \mathrm{C}$, and the other sample is $125^{\circ} \mathrm{C}$ except for the $S_{1}$ at $121{ }^{\circ} \mathrm{C}$.

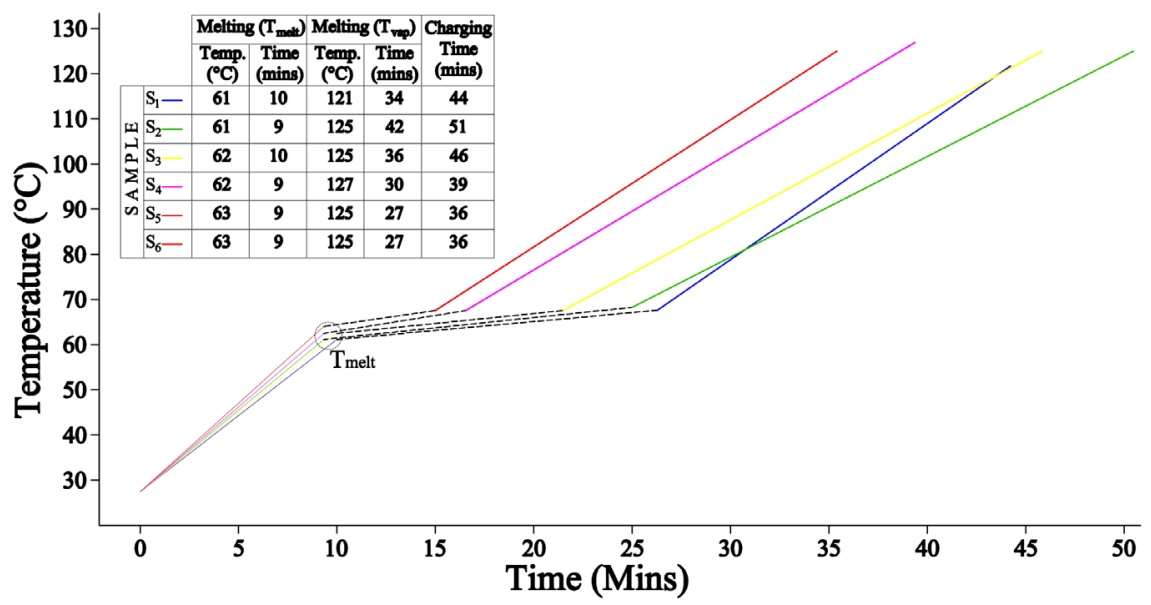

Fig. 3. Charging test for all composite sample

\section{2. Results of discharging test}

During discharging (Fig. 4), it can be seen that the discharging for pure paraffin is too slow and takes 225 minutes to reach room temperature $\left(T_{a m b}\right)$. A longer discharging process makes the paraffin is kinetically unfavorable, and it indicates that the power rate of pure paraffin is low, which undesirable for the application. Furthermore, the solidification is started at $54{ }^{\circ} \mathrm{C}$ where the melting process occurred at $62{ }^{\circ} \mathrm{C}$; thus, the supercooling phenomenon takes in place. The supercooling phenomenon should be avoided for phase change material application because the phase change of the material is hard to predict, and the energy released could be far from as expected. The main factor of supercooling in paraffin is due to the low kinetic nature of paraffin during solidification and makes the nucleation and crystal growth slower at occurs at a lower temperature.

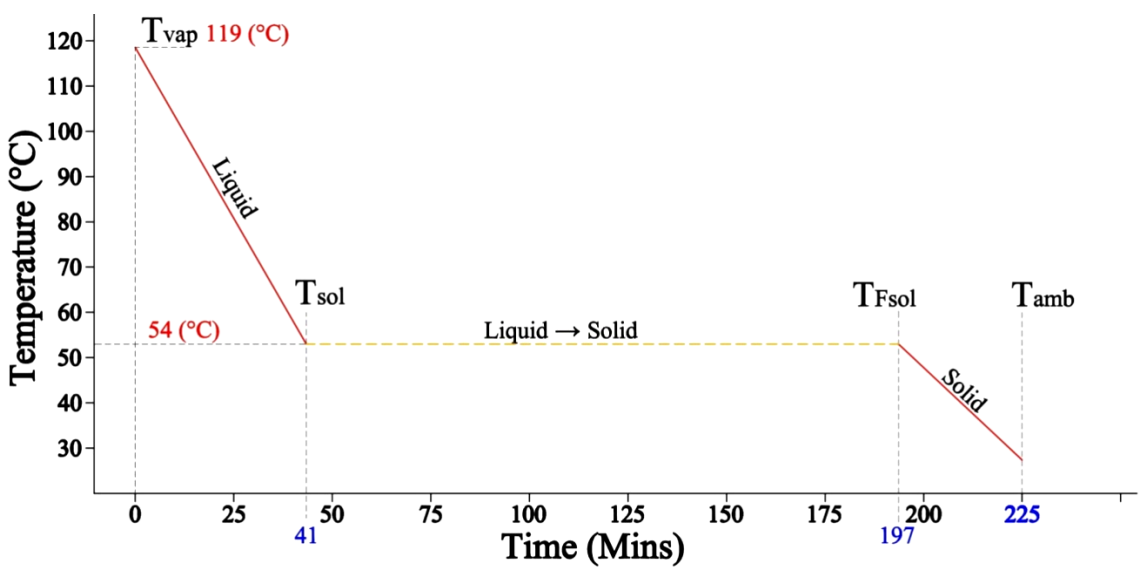

Fig. 4. The time vs temperature changes for pure paraffin during discharging

The characteristic of the composite samples during discharging provides much valuable information and is shown in Fig. 5. Some important keys can be obtained from the discharging test. The required time for the samples to reach initial solid temperature $\left(T_{\text {sol }}\right)$ during initial solidifying (thin line) is relatively the same, but it varies significantly during a partial phase change (dashed line) from $T_{s o l}$ to $T_{F s o l}$ and cooling time from $T_{F s o l}$ to $T_{a m b}$ (thick line). The temperature decreased faster for the sample with larger sand particle size $\left(S_{1}, S_{3}\right.$ and $\left.S_{5}\right)$ rather than smaller particle size $\left(S_{2}, S_{4}\right.$ and $\left.S_{6}\right)$. Larger particle size $(74 \mu \mathrm{m})$ has a higher density compared to $44 \mathrm{um}$ and it affects the temperature distribution within the composite and accelerated the heat releasing from the material. 


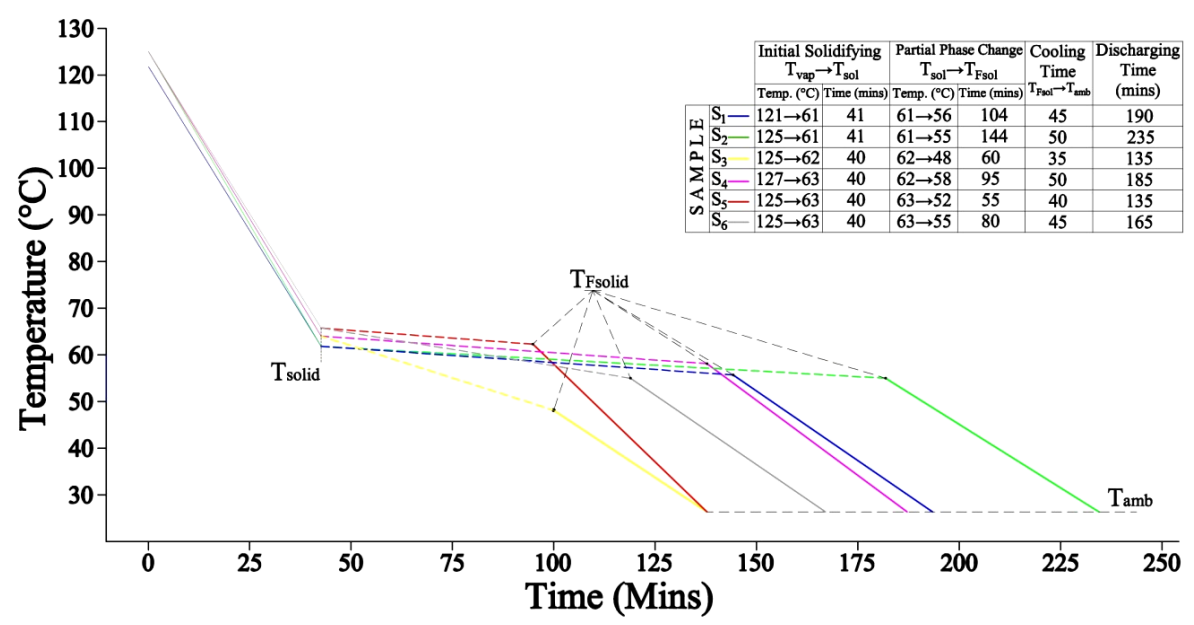

Fig. 5. Discharging test for all composite sample

The saturated solid temperature $\left(T_{F s o l}\right)$ is indicated when the temperature decreased significantly until room temperature (thick mark, $T_{a m b}$ ). Compared to the data from charging (Fig. 3), it is observed that the saturated solid temperature for discharging is lower than the melting temperature $\left(T_{m e l t}\right)$ during charging, which is marked as a supercooling phenomenon.

\section{Discussion}

The initial step needs to be done is examine the volcanic ash. The examination is focused on the chemical composition of the sand. Experimental testing is conducted by mixing sand and paraffin as a composite phase change material. The mass fraction and sand grain size are used as the variations of the composite. The experimental results of the composite provide the charging and discharging rate at specific time and temperature, where it can be analyzed to determine the supercooling effect. Thus, the effect of the sand in paraffin as composite PCM can be made based on the chemical composition of the sand and the experimental result, and it can be used as a reliable reference for the development of composite PCM as excellence thermal energy storage.

Pure paraffin has a low thermal conductivity so the temperature increment during charging process is slow. Fig. 2 shows obviously that the pure paraffin during charging has three different phase transitions where the melting temperature occurs at $62{ }^{\circ} \mathrm{C}$ within 52 minutes. The addition of volcanic sand for all composite samples able to increase the charging rate of pure paraffin. It can be observed from Fig. 3 where the charging rate becomes faster which makes the charging performance of paraffin is increased as the presence of sand. The compositions of volcanic sand are dominated with high thermal conductivity material which help to accelerate the heat transfer process within the composite. Adding $50 \mathrm{wt}$. \% of volcanic sand able to improve the charging rate significantly where the vapor temperature is reached within 36 minutes. The melting temperature for all composite samples is relatively same as the melting temperature of pure paraffin. According to that, the addition of sand is only increasing the charging rate with a minor effect on melting temperature. Besides, the mushy region is observed for all composite samples which indicates partial phase change is occurred.

During discharging, the effect of low thermal conductivity on pure paraffin is observed clearly. It takes 225 minutes for pure paraffin to release the stored heat energy from temperature $119^{\circ} \mathrm{C}$ to $30^{\circ} \mathrm{C}$. Phase transition of pure paraffin during discharging (Fig. 4) is longer which indicates unstable phase transition is occurred. The addition of sand able to reduce the drawbacks of low thermal conductivity on paraffin where the discharging performance for composite samples is generally better with a faster discharging rate (Fig. 5). The mushy region is also observed during discharging which helps to shortened the phase transition. Even though there is an anomaly for $S_{2}$, the others composite shows an identical pattern which more sand contains on the paraffin able to accelerated the discharging process. 
The addition of sand which consists of high thermal conductivity materials able to improve the charging and discharging performance of pure paraffin. It helps to promote a better power rate which is desirable for most application of latent heat storage. High power rate of latent heat storage able to reduce the charging and discharging time which is ideal for the application of latent heat storage, particularly for temperature sensitive application like thermal management system. The addition of sand able to reduce the supercooling phenomenon which is undesirable. $S_{5}$ has the lowest supercooling degree, which only $1{ }^{\circ} \mathrm{C}$. Low supercooling degree provides a suitable temperature prediction for the application and makes the system more reliable since the system can work precisely.

It shows that the addition of volcanic sand to the paraffin as latent heat storage is advantageous. The overall performance of pure paraffin is increased depends on the ratio which helps to set a specific characteristic. Nevertheless, adding volcanic sand as thermal conductivity enhancement is decreased the thermal capacity since it works based on temperature gradient. Therefore, it is important to adjust the capacity of the storage according to the load. Further research is needed to obtain the most suitable ratio of the paraffin and sand which has the most suitable performance and life cycle assessment for the composite to evaluate the aging effect on the composite's performance.

\section{Conclusions}

1. The properties of the sand from volcanic ash is ideal to improve the performance of paraffinic PCM.

2. The main compositions of the sand are $\mathrm{Fe}, \mathrm{Fe}_{2} \mathrm{O}_{3}$ and $\mathrm{SiO}_{2}$ dominate the chemical composition of the sand (total $85.47 \%$ ), which is known have good thermal conductivity, with the total composition of $85.47 \%$.

3. The rate of charging for all composite PCM is better than pure paraffin where the quickest charging rate is 36 minutes.

4. The rate of discharging for all composite PCM is generally better than pure paraffin where the quickest charging rate is 135 minutes.

5. The lowest supercooling degree is obtained by $1{ }^{\circ} \mathrm{C}$, which is better than pure paraffin where it has supercooling degree $8{ }^{\circ} \mathrm{C}$.

\section{References}

[1] Kanimozhi, B., Harish, K., Tarun, B. S., Sainath Reddy, P. S., Sujeeth, P. S. (2017). Charging and Discharging Processes of Thermal Energy Storage System Using Phase change materials. IOP Conference Series: Materials Science and Engineering, 197, 012040. doi: https://doi.org/10.1088/1757-899x/197/1/012040

[2] Ismail, I., Rahman, R. A., Haryanto, G., Pane, E. A. (2021). The Optimal Pitch Distance for Maximizing the Power Ratio for Savonius Turbine on Inline Configuration. International Journal of Renewable Energy Research, 11 (2), 595-599.

[3] Praveen, B., Suresh, S. (2018). Experimental study on heat transfer performance of neopentyl glycol/CuO composite solidsolid PCM in TES based heat sink. Engineering Science and Technology, an International Journal, 21 (5), $1086-1094$. doi: https://doi.org/10.1016/j.jestch.2018.07.010

[4] Klarzak, I., Ura-Bińczyk, E., Płocińska, M., Jurczyk-Kowalska, M. (2018). Effect of temperature and humidity on heat effect of commercial chemical warmers based on iron powder. Thermal Science and Engineering Progress, 6, 87-94. doi: https://doi.org/10.1016/j.tsep.2018.03.006

[5] Liu, Y., Yu, K., Lu, S., Wang, C., Li, X., Yang, Y. (2020). Experimental research on an environment-friendly form-stable phase change material incorporating modified rice husk ash for thermal energy storage. Journal of Energy Storage, 31, 101599. doi: https://doi.org/10.1016/j.est.2020.101599

[6] Rahmalina, D., Rahman, R. A., Suwandi, A., Ismail (2020). The recent development on MgH2 system by 16 wt\% nickel addition and particle size reduction through ball milling: A noticeable hydrogen capacity up to $5 \mathrm{wt} \%$ at low temperature and pressure. International Journal of Hydrogen Energy, 45 (53), 29046-29058. doi: https://doi.org/10.1016/j.ijhydene.2020.07.209

[7] Hailu, G., Hayes, P., Masteller, M. (2017). Seasonal Solar Thermal Energy Sand-Bed Storage in a Region with Extended Freezing Periods: Part I Experimental Investigation. Energies, 10 (11), 1873. doi: https://doi.org/10.3390/en10111873

[8] Mhiri, H., Jemni, A., Sammouda, H. (2020). Numerical and experimental investigations of melting process of composite material (nanoPCM/carbon foam) used for thermal energy storage. Journal of Energy Storage, 29, 101167. doi: https://doi.org/ 10.1016/j.est.2019.101167 
[9] George, M., Pandey, A. K., Rahim, N. A., Tyagi, V. V., Shahabuddin, S., Saidur, R. (2020). Long-term thermophysical behavior of paraffin wax and paraffin wax/polyaniline (PANI) composite phase change materials. Journal of Energy Storage, 31, 101568. doi: https://doi.org/10.1016/j.est.2020.101568

[10] Reyes, A., Henríquez-Vargas, L., Rivera, J., Sepúlveda, F. (2017). Theoretical and experimental study of aluminum foils and paraffin wax mixtures as thermal energy storage material. Renewable Energy, 101, 225-235. doi: https://doi.org/10.1016/ j.renene.2016.08.057

[11] Ahmed, N., Elfeky, K. E., Lu, L., Wang, Q. W. (2020). Thermal performance analysis of thermocline combined sensible-latent heat storage system using cascaded-layered PCM designs for medium temperature applications. Renewable Energy, 152, 684-697. doi: https://doi.org/10.1016/j.renene.2020.01.073

[12] Sivapalan, B., Neelesh Chandran, M., Manikandan, S., Saranprabhu, M. K., Pavithra, S., Rajan, K. S. (2018). Paraffin wax-water nanoemulsion: A superior thermal energy storage medium providing higher rate of thermal energy storage per unit heat exchanger volume than water and paraffin wax. Energy Conversion and Management, 162, 109-117. doi: https://doi.org/10.1016/ j.enconman.2018.01.073

[13] Elbahjaoui, R., El Qarnia, H. (2019). Performance evaluation of a solar thermal energy storage system using nanoparticle-enhanced phase change material. International Journal of Hydrogen Energy, 44 (3), 2013-2028. doi: https://oi.org/10.1016/ j.ijhydene.2018.11.116

[14] Zhang, P., Meng, Z. N., Zhu, H., Wang, Y. L., Peng, S. P. (2017). Melting heat transfer characteristics of a composite phase change material fabricated by paraffin and metal foam. Applied Energy, 185, 1971-1983. doi: https://doi.org/10.1016/ j.apenergy.2015.10.075

[15] Frazzica, A., Manzan, M., Sapienza, A., Freni, A., Toniato, G., Restuccia, G. (2016). Experimental testing of a hybrid sensiblelatent heat storage system for domestic hot water applications. Applied Energy, 183, 1157-1167. doi: https://doi.org/10.1016/ j.apenergy.2016.09.076

[16] Palacios, A., Elena Navarro, M., Barreneche, C., Ding, Y. (2020). Hybrid 3 in 1 thermal energy storage system - Outlook for a novel storage strategy. Applied Energy, 274, 115024. doi: https://doi.org/10.1016/j.apenergy.2020.115024

[17] Drissi, S., Ling, T.-C., Mo, K. H. (2019). Thermal efficiency and durability performances of paraffinic phase change materials with enhanced thermal conductivity - A review. Thermochimica Acta, 673, 198-210. doi: https://doi.org/10.1016/ j.tca.2019.01.020

[18] Diago, M., Iniesta, A. C., Soum-Glaude, A., Calvet, N. (2018). Characterization of desert sand to be used as a high-temperature thermal energy storage medium in particle solar receiver technology. Applied Energy, 216, 402-413. doi: https://doi.org/ 10.1016/j.apenergy.2018.02.106

[19] Ismail, I., John, J., Pane, E. A., Maulana, R., Rahman, R. A., Suwandi, A. (2021). Experimental Evaluation for The Feasibility of Test Chamber in The Open-Loop Wind Tunnel. WSEAS Transactions on Fluid Mechanics, 16, 120-126. doi: https://doi.org/ 10.37394/232013.2021.16.12

[20] Tiskatine, R., Oaddi, R., Ait El Cadi, R., Bazgaou, A., Bouirden, L., Aharoune, A., Ihlal, A. (2017). Suitability and characteristics of rocks for sensible heat storage in CSP plants. Solar Energy Materials and Solar Cells, 169, 245-257. doi: https://doi.org/ 10.1016/j.solmat.2017.05.033

[21] Welsford, C., Bayomy, A. M., Saghir, M. Z. (2018). Role of metallic foam in heat storage in the presence of nanofluid and microencapsulated phase change material. Thermal Science and Engineering Progress, 7, 61-69. doi: https://doi.org/10.1016/ j.tsep.2018.05.003

[22] Bai, Z., Miao, Y., Xu, H., Gao, Q. (2020). Experimental study on thermal storage and heat transfer performance of microencapsulated phase-change material slurry. Thermal Science and Engineering Progress, 17, 100362. doi: https://doi.org/10.1016/ j.tsep.2019.100362

[23] Khan, A. I., Valan Arasu, A. (2019). A review of influence of nanoparticle synthesis and geometrical parameters on thermophysical properties and stability of nanofluids. Thermal Science and Engineering Progress, 11, 334-364. doi: https://oi.org/ 10.1016/j.tsep.2019.04.010

[24] Mahdi, M. S., Mahood, H. B., Hasan, A. F., Khadom, A. A., Campbell, A. N. (2019). Numerical study on the effect of the location of the phase change material in a concentric double pipe latent heat thermal energy storage unit. Thermal Science and Engineering Progress, 11, 40-49. doi: https://doi.org/10.1016/j.tsep.2019.03.007

[25] Zhang, P., Hu, Y., Song, L., Lu, H., Wang, J., Liu, Q. (2009). Synergistic effect of iron and intumescent flame retardant on shape-stabilized phase change material. Thermochimica Acta, 487 (1-2), 74-79. doi: https://doi.org/10.1016/j.tca.2009.01.006

[26] Janu, V. C., Bahuguna, G., Laishram, D., Shejale, K. P., Kumar, N., Sharma, R. K., Gupta, R. (2018). Surface fluorination of $\alpha-\mathrm{Fe}_{2} \mathrm{O}_{3}$ using selectfluor for enhancement in photoelectrochemical properties. Solar Energy Materials and Solar Cells, 174, 240-247. doi: https://doi.org/10.1016/j.solmat.2017.09.006 
[27] Hezaveh, H., Fazlali, A., Noshadi, I. (2012). Synthesis, rheological properties and magnetoviscos effect of Fe2O3/paraffin ferrofluids. Journal of the Taiwan Institute of Chemical Engineers, 43 (1), 159-164. doi: https://doi.org/10.1016/j.jtice.2011.07.003

[28] Hu, M., Yan, Z., Peng, L., Guo, N., Liu, Z. (2019). Optimization of preparation and analysis of Paraffin/SiO2 composite PCMs via sol-gel method. IOP Conference Series: Earth and Environmental Science, 242, 032005. doi: https://oi.org/10.1088/ $1755-1315 / 242 / 3 / 032005$

[29] Şahan, N., Paksoy, H. (2017). Determining influences of SiO2 encapsulation on thermal energy storage properties of different phase change materials. Solar Energy Materials and Solar Cells, 159, 1-7. doi: https://doi.org/10.1016/j.solmat.2016.08.030

[30] Kılıçkap, S., El, E., Yıldız, C. (2018). Investigation of the effect on the efficiency of phase change material placed in solar collector tank. Thermal Science and Engineering Progress, 5, 25-31. doi: https://doi.org/10.1016/j.tsep.2017.10.016

[31] Venkateshwar, K., Tasnim, S. H., Simha, H., Mahmud, S. (2020). Effect of spatially varying morphologies of metal foams on phase change process. Thermal Science and Engineering Progress, 19, 100667. doi: https://doi.org/10.1016/j.tsep.2020.100667

Received date 25.03.2021

(C) The Author(s) 2021

Accepted date 10.09.2021

This is an open access article

Published date 10.01.2022 under the Creative Commons CC BY license

How to cite: Rahmalina, D., Adhitya, D. C., Rahman, R. A., Ismail, I. (2022). Improvement the performance of composite PCM paraffin-based incorporate with volcanic ash as heat storage for low-temperature application. EUREKA: Physics and Engineering, 1, 53-61. doi: https://doi.org/10.21303/2461-4262.2022.002055 